\title{
Long-term growth hormone treatment in a boy with 45,X/46,X,idic(Yp) mixed gonadal dysgenesis: comparison with growth pattern of an untreated patient
}

\author{
Silvano Bertelloni, ${ }^{1}$ Eleonora Dati, ${ }^{2}$ Angelo Valetto, ${ }^{3}$ Veronica Bertini, ${ }^{3}$ \\ Alfredo Danti, ${ }^{4}$ Giampiero I. Baroncelli ${ }^{1}$
}

${ }^{1}$ Adolescent Medicine, I Pediatric Division, Department of Obstetrics, Gynecology and Pediatrics; ${ }^{2}$ Division of Pediatric Oncology, Department of Obstetrics, Gynecology and Pediatrics; ${ }^{3}$ Laboratory of Medical Genetics, Department of Laboratory Medicine; Azienda Ospedaliero-Universitaria Pisana, Pisa; ${ }^{4}$ Department of Pediatric Urology, Pediatric Hospital "A. Meyer", Florence; Italy

\begin{abstract}
BACKGROUND: Mixed gonadal dysgenesis (MGD) is a rare disorder. Short stature is a well known feature of this condition. Although growth hormone (GH) treatment has been suggested to treat growth impairment, conflicting data surround this issue. CASE REPORT: We report on long-term growth hormone (GH) therapy at pharmacological doses $(0.33 \mathrm{mg} / \mathrm{kg} / \mathrm{week})$ in a boy (age 4.6 years) with MGD [karyotype 45,X/46,X,idic(Yp)]. An untreated boy of similar karyotype and growth delay served as control. The treated boy showed a progressive improvement of stature during GH administration. His height completely normalized after 6.5 years of treatment and he reached his target height centile before puberty onset. In the untreated boy, no improvement of growth pattern was found. CONCLUSIONS: We conclude that short boys with MGD and 45,X/46,X,idic(Yp) karyotype may benefit from early GH therapy at pharmacological doses. Evaluation of larger patient samples and additional follow-up till final height are needed to reach definitive conclusions as to the optimal growth-promoting therapy for this disorder of sex development.
\end{abstract}

Key words: 45,X/46,X,idic(Yp), Growth hormone treatment, Karyotype, Mixed gonadal dysgenesis, Short stature, SHOX

\section{INTRODUCTION}

Isodicentrics $\mathrm{Yp}$ (idicY) are structural anomalies

Address for correspondence:

Silvano Bertelloni, MD, Dipartimento Materno-infantile,

Ospedale Santa Chiara - AOUP, Via Roma 67, 56125 Pisa, Italy,

Tel.: +39-050-992743, Fax: +39-050-992641,

E-mail: s.bertelloni@med.unipi.it

Received 20-6-2013, Accepted 25-10-2013 of the $\mathrm{Y}$ chromosome associated with a $45, \mathrm{X}$ cell line and a broad spectrum of disordered sex development. The presence of a $45, \mathrm{X}$ cell line is a direct consequence of the instability of the rearranged $\mathrm{Y}$ chromosome. ${ }^{1}$ The percentage of $45, \mathrm{X}$ cells in the urogenital ridge during the critical time window of SRY action likely plays a major role in abnormal sex determination and differentiation of the gonads. In fact, the transcripts 
produced by the two copies of the SRY gene on the idic(Yp) could be diluted by the 45 ,X cell line; therefore, their level may be below the critical threshold necessary for testicular formation, resulting in mixed gonadal dysgenesis (MGD). ${ }^{2,3}$

MGD is rare $(0.23 / 1,000$ amniocenteses or $1.7 / 10,000$ newborns). ${ }^{3,4}$ At birth, children with MGD present with ambiguous external genitalia. ${ }^{5-7}$ They are often reared as boys and corrective surgery of anatomical abnormalities are performed early for the reason that the unilateral scrotal testis might have potential for testosterone secretion, spontaneous onset of puberty and some reproductive ability. ${ }^{5-8}$

Short stature is a well known feature of boys with MGD and 45,X/46,XY or 45,X/46,X,idic(Yp) mosaicism. ${ }^{4-7}$ Although short stature does not seem to be due to growth hormone $(\mathrm{GH})$ deficiency, $\mathrm{GH}$ treatment has been reported in some papers showing a short-term beneficial effect on growth., ${ }^{7,-11}$

In this paper, we report on long-term follow-up of two boys with $45, \mathrm{X} / 46$, X,idic(Yp) karyotype, ambiguous genitalia at birth and short stature, one of whom underwent recombinant GH treatment, while the untreated boy served as control.

\section{CASE REPORT}

Two boys (\#PI020 and \#PI036) with MGD came to our attention on account of short stature (Table 1). Both patients were born from uncomplicated pregnancies, but presented ambiguous genitalia at birth (Sinnecker grade 3 ) ${ }^{12}$ birth weight of both was slightly reduced, while birth length was reduced according to Italian reference standards only in \#PI020 (Table 1). ${ }^{13}$ In both babies, a 45,X/46,X,idic(Yp) karyotype was found in peripheral blood cells (Table 1); a higher percentage of the 45,X line in fibroblasts rather than in leukocytes was found in \#PI020 (Table 1); fibroblast karyotyping was not performed in \#PI036. Male sex was assigned in both babies. Corrective surgery of the severe hypospadias was performed during the first 18 months of life; at the same time, the streak gonad (left in \#PI020; right in \#PI036) was removed and the controlateral testis was fixed into the scrotum. Midparental height (MPH) was $171.3 \mathrm{~cm}$ (-0.48 SDS) and $172.5 \mathrm{~cm}(-0.33 \mathrm{SDS})$ in \#PI020 and \#PI036, respectively. At first visit, height was -2.5 SDS and -1.5 SDS in \#PI020 and \#PI036, respectively, and was declining in the former (Figure 1). In both boys, $\mathrm{GH}$ deficiency was not found (GH peaks $>10 \mathrm{ng} / \mathrm{ml}$

Table 1. Auxological findings of the two boys with mixed gonadal dysgenesis

\begin{tabular}{lcc}
\hline & Boy \#PI020 & Boy \#PI036 \\
\hline Birth length, cm (SDS) & $47(-2.28)$ & $52(0.62)$ \\
Birth weight, kg (SDS) & $3.0(-1.48)$ & $3.2(-0.74)$ \\
Karyotype & $45, \mathrm{X}(15 \%) 46, \mathrm{X}, \mathrm{idic}(\mathrm{Yp})(85 \%)^{*}$ & $45, \mathrm{X}(30 \%) 46, \mathrm{X}, \mathrm{idic}(\mathrm{Yp})(70 \%)$ \\
Age at first visit, years & $4,6 / 12$ & 4 \\
Height, cm (SDS) & $93.5(-2.5)$ & $92.0(-1.5)$ \\
Height velocity, cm/year (SDS) & $3.8(-2.5)^{\circ}$ & - \\
BMI, kg/m & 15.2 & 16 \\
SPAM, cm & 93.0 & - \\
Bone age, years & 3.5 & 4.0 \\
Age at last visit, years & 11.0 & $11,4 / 12$ \\
Height, cm (SDS) & $140(-0.3)$ & $132.3(-1.8)$ \\
BMI, kg/m & 20.9 & 17.7 \\
SPAM, cm & 139.0 & 132.0 \\
Bone age, years & 10.5 & 11.0 \\
PAH, cm (SDS) & $176.1(0.20)$ & $164.8(-1.49)$ \\
Pubertal stage & G1, Ph1 & G1, Ph1 \\
\hline
\end{tabular}

PAH $=$ predicted adult height; $*$ fibroblast karyotype 45,X(86\%)/46,X,idic(Yp)(14\%); ${ }^{\circ}$ during the last 6 months before first visit (based on measurement by family pediatrician). 
during two provocative GH tests). IGF1 values were in the normal range but below the mean in both boys [\#PI020: 152 ng/ml (-1.3 SDS); \#PI036: 204 ng/ml (-0.8 SDS)]. Body mass index was normal (Table 1$)$.

The occurrence of occult celiac disease or other chronic gastrointestinal disorder was ruled out by appropriate biochemical analysis in both boys; reactive
C protein, thyroid values, renal function and albumin levels were normal (data not shown).

Boy \#PI020 started treatment with recombinant GH at the dose of $0.33 \mathrm{mg} / \mathrm{kg} /$ week. During treatment, the dose was adjusted according to the increase in body weight and to maintain IGF1 serum levels between 0 and +2.0 SDS. Height progressively increased into

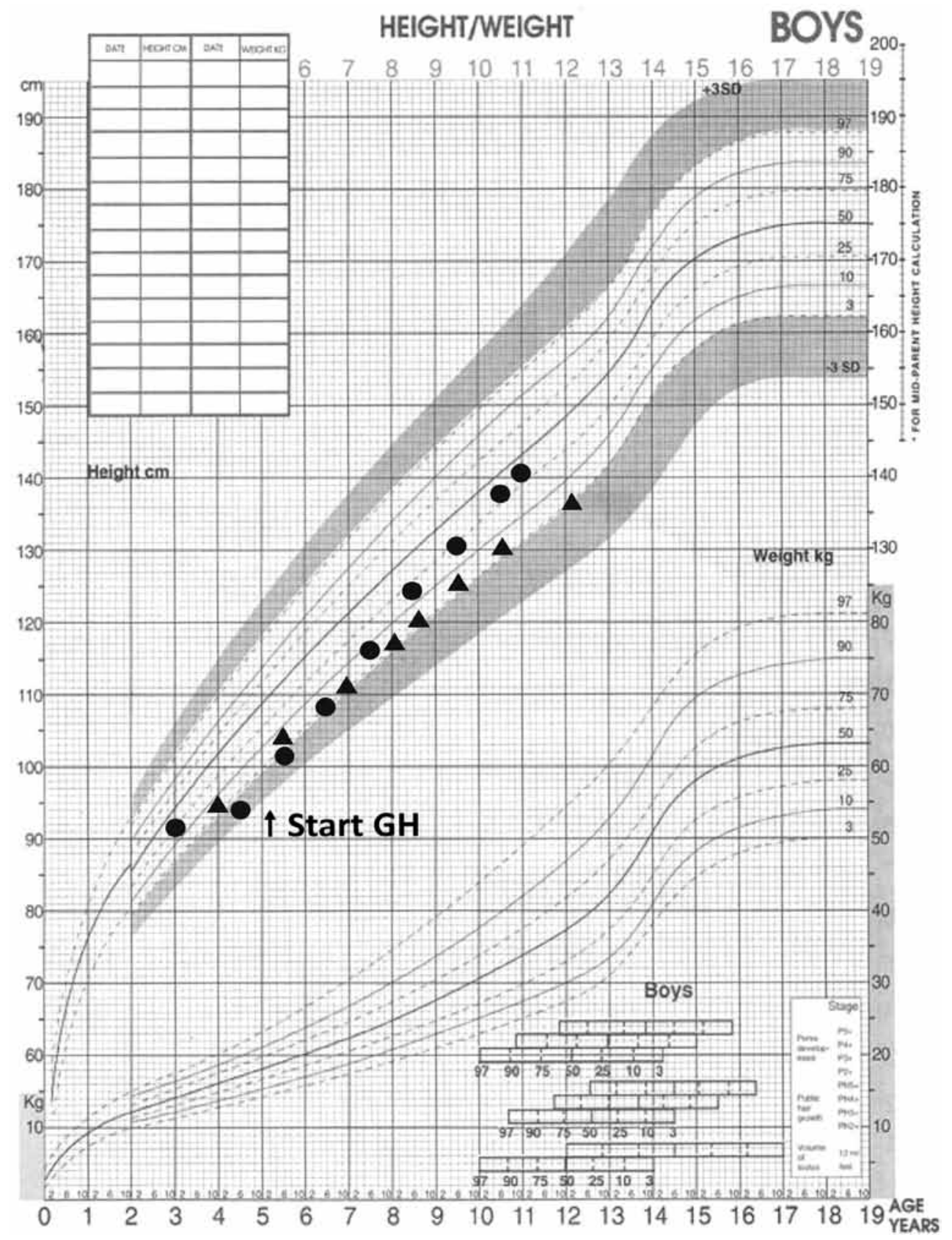

Figure 1. Growth curves of two boys with 45,X/46,X,idic(Yp) mixed gonadal dysgenesis treated $(\bullet)$ or not ( $\mathbf{\Delta})$ with recombinant GH. 
normal range approaching the $50^{\text {th }}$ centile at the age 11.0 years (Figure 1). Height was -2.5 SDS before GH treatment and progressively rose to $-0.3 \mathrm{SDS}$ at last evaluation, reaching his MPH (Figure 2). The growth curve of the untreated boy remained near the $3^{\text {rd }}$ centile during follow-up (Figure 1). At last visit, predicted adult height (PAH) of the treated boy was adequate in respect to his MPH (Table 1). On the contrary, the PAH of the untreated boy remained below both his own MPH and that of the treated patient (Table 1). No adverse event pertaining to GH treatment was recorded.

Informed consent by the parents of both boys was obtained before any diagnostic or therapeutic intervention. Genital ambiguity was ranked according to Sinnecker et al. ${ }^{12}$ Centiles of birth weight and length were calculated according to Italian reference standards; ${ }^{13}$ postnatal height was expressed as raw measured values and as standard deviation scores (SDS) according to Tanner et al. ${ }^{14}$ Bone age was assessed according to the method of Greulich and Pyle $;^{15}$ PAH was calculated in accordance with the Bayley and Pinneau tables. ${ }^{16} \mathrm{MPH}$ was calculated using measured parental heights adjusted for male $\operatorname{sex}[($ father height + mother height $) / 2)+6.5 \mathrm{~cm}]$.

Baseline blood samples were obtained in the fasting state between 8.00 and 9.00 a.m.; GH secretion in response to the arginine provocative test $(0.5 \mathrm{mg} /$ $\mathrm{kg} / \mathrm{i}$.v. $)$ and insulin tolerance test $(0.1 \mathrm{IU} / \mathrm{kg} / \mathrm{i} . \mathrm{v}$. $)$ was assessed with sampling at $0,30,60,90$ and 120 minutes (normal response $=\mathrm{GH}$ peak $>10 \mathrm{ng} / \mathrm{ml}$ ). All

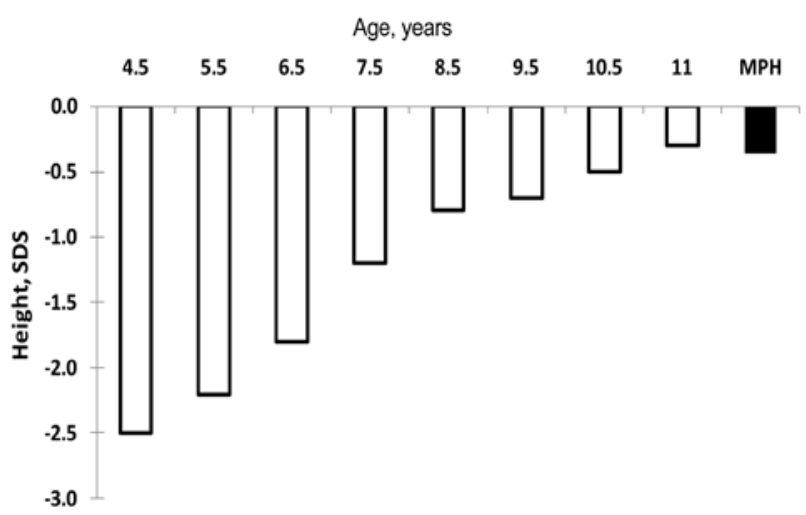

Figure 2. Progressive improvement of height SDS in the boy with 45,X/46,X,idic(Yp) mixed gonadal dysgenesis during recombinant $\mathrm{GH}$ treatment $(\mathrm{MPH}=$ mid parental height $)$. serum samples were kept at $-80^{\circ} \mathrm{C}$ up till laboratory assessment. Serum levels of GH and IGF1 (reference values for prepubertal children $277 \pm 93 \mathrm{ng} / \mathrm{ml}$ ) were determined as previously reported. ${ }^{17}$

Chromosome analysis was performed on peripheral blood lymphocyte cultures using conventional techniques ( $\mathrm{G}$ and Q-banding at 550 band level). In order to detect low-level mosaicisms, more than 100 metaphases were analyzed. Molecular cytogenetic techniques were used to better characterize the $\mathrm{Y}$ chromosome derivative. FISH (fluorescence in situ hybridization) was performed with a whole Y chromosome painting probe (BOUTY, Cambridge, UK) as well as probes specific for the SRY gene and the Y centromeric alphoid probe, DYZ3 (Vysis, Downers Grove, IL).

\section{DISCUSSION}

In this paper, we report the long-term effects of recombinant $\mathrm{GH}$ treatment on the growth pattern of a child with 45,X/46,X,idic(Yp) MGD and short stature. In this boy, growth delay was present at birth and worsened around the age of 3 years. Meanwhile, the height curve paralleled the $3^{\text {rd }}$ centile in an untreated boy who had similar a karyotype in leukocytes but normal growth parameters at birth.

The differences in prenatal growth pattern may be related to a different mosaicism in the $45, \mathrm{X}$ line between the two boys, but the fibroblast karyotype was available only for boy \#PI020. Thus, this hypothesis should be verified via additional cytogenetic studies. At any rate, the high percentage of $45, \mathrm{X}$ fibroblasts in boy \#PI020 may explain the low birth length and weight, as reported in girls with Turner syndrome, ${ }^{18}$ since his mother's pregnancy was uncomplicated by known disorders affecting fetal growth. ${ }^{19}$

Although the cause of postnatal growth impairment is largely unknown, it is a well reported feature of boys with MGD, ${ }^{5,6,9-11}$ which leads to short adult height. ${ }^{5,6}$ Classic GH deficiency likely does not occur in this disorder, ${ }^{6,7}$ as confirmed by the normal $\mathrm{GH}$ response to provocative stimuli in both the present boys. Although appropriate IGF1 values for delayed bone age has been reported in one boy, ${ }^{10}$ the low normal or slightly reduced IGF1 reported in this and 
in other studies ${ }^{7,9}$ may suggest some degree of $\mathrm{GH}$ resistance in the presence of the normal GH secretion, as we found. This hypothesis may be supported by the evidence that serum IGF1 concentrations remained in the normal range during GH treatment at pharmacological doses in our own and in other patients. ${ }^{9}$ In addition, as in girls with Turner syndrome, ${ }^{20}$ SHOX gene haploinsufficiency in the $45, \mathrm{X}$ cell line may play a role in the growth impairment and may explain the growth improvement during $\mathrm{GH}$ administration. In fact, girls with Turner syndrome and children with SHOX deficiency alike benefit from GH treatment..$^{21-24}$ In addition, Y chromosome rearrangement with loss of possible Y-growth gene(s) (GGY) and prenatal growth retardation may contribute to growth impairment. ${ }^{25,26}$

Response to GH treatment in boys with MGD and short stature has been assessed in few studies. ${ }^{5-7,9-11}$ Improvement of linear growth has been documented; however, the majority of reported patients started treatment at a late chronological age ( $>10$ years) and only short follow-up periods were provided or only final height was retrospectively assessed..$^{5-7,9-11}$ Thus, the outcome of early and long-term treated boys is largely unknown. Among the 6 boys described by Richter-Unruh et al, ${ }^{9}$ only one patient was treated for more than 5 years. His height increased from -2.68 SDS to -1.34 SDS, but GH therapy was started at the age of 10.5 years. Martinerie et al retrospectively described the height outcome of 13 boys treated with GH for a mean period of 6.5 years; no significant difference in final height was found in comparison with that of an untreated group $(157 \pm 2.3 \mathrm{~cm}$ vs $156.6 \pm 4.2$ $\mathrm{cm}$, respectively). ${ }^{5}$ Only 5 patients were treated early (between 4 and 7 years) and 4 boys of this subgroup reached final height. ${ }^{5}$ Again, no significant difference was evident between these early treated boys in comparison with those treated after the chronological age of 10 years $(\mathrm{n}=8)(157 \pm 5.2 \mathrm{~cm}$ vs $155.9 \pm 6.5 \mathrm{~cm}$, respectively), ${ }^{5}$ but $\mathrm{GH}$ was administered at relatively low dose (0.17-0.24 mg/kg/week) in comparison with our own and other studies. ${ }^{6,7,9,10}$ In addition, GH dose was not adjusted according to IGF1 levels. ${ }^{5} \mathrm{~A}$ boy of 7.8 years was treated with GH in the study of Tosson et al.$^{6}$ His final height was $164.7 \mathrm{~cm}$, similar to that of the three patients treated at older ages or that of the three untreated children $(\mathrm{cm} \mathrm{159.1 \pm 8.7}$ and $\mathrm{cm} 162.5 \pm 3.8$, respectively); however, neither the GH dose used in this child nor the duration of GH therapy was presented. ${ }^{6}$ In our boy treated with pharmacological doses of $\mathrm{GH}$, growth pattern normalized before the onset of puberty, while the untreated control did not show any amelioration of his height. Predicted adult height was above MPH in the treated boy, while the untreated boy showed poor predicted adult height that resulted in an adult height similar to that of untreated men with 45,X/46,XY MGD. ${ }^{5,6}$ Thus, we suggest that early initiation of GH therapy, long duration of therapy and high GH doses progressively modified according to the patient's growth response and IGF1 levels may produce a better outcome, normalizing growth pattern before the onset of puberty, as in Turner syndrome. ${ }^{23}$ In addition, prenatal growth impairment and the evidence of a high percentage of 45, $X$ cells in fibroblasts, since they have originated from the same mesenchimal stem cells of chondrocytes and osteoblasts, ${ }^{27}$ may be additional criteria for GH treatment. ${ }^{19,23,24}$

In order to reach definitive conclusions for the purposes of clinical practice regarding this disorder, reports must be made available of larger numbers of patients in whom multiple tissue karyotyping has been carried out. In addition, growth pattern during puberty and its "tempo", which may be impaired by SHOX haploinsufficiency, GH treatment, possibly deranged sex steroid production, and longer followup till attainment of adult height should be evaluated to optimize management of growth delay in MGD.

\section{REFERENCES}

1. Hsu LY, 1994 Phenotype/karyotype correlations of Y chromosome aneuploidy with emphasis on structural aberrations in postnatally diagnosed cases. Am J Med Genet 53: 108-140.

2. Sekido R, Lovell-Badge R, 2009 Sex determination and SRY: down to a wink and a nudge? Trend Genetic 25: 19-29.

3. Huang B, Thangavelu M, Bhatt S, J Sandlin C, Wang S, 2002 Prenatal diagnosis of 45,X and 45,X mosaicism: the need for thorough cytogenetic and clinical evaluations. Prenat Diagn 22: 105-110.

4. Chang HJ, Clark RD, Bachman H, 1990 The phenotype of 45,X/46,XY mosaicism: an analysis of 92 prenatally diagnosed cases. Am J Hum Genet 46: 156-167.

5. Martinerie L, Morel Y, Gay CL, et al, 2012 Impaired puberty, fertility, and final stature in $45, \mathrm{X} / 46, \mathrm{XY}$ mixed 
gonadal dysgenetic patients raised as boys. Eur J Endocrinol 166: 687-694.

6. Tosson H, Rose SR, Gartner LA, 2010 Children with 45,X/46,XY karyotype from birth to adult height.Horm Res Paediatr 74: 190-200.

7. Lindhardt Johansen M, Hagen CP, Rajpert-De Meyts E, et al, 2012 45,X/46,XY mosaicism: phenotypic characteristics, growth, and reproductive function--a retrospective longitudinal study. J Clin Endocrinol Metab 97: E1540-1549.

8. Knudtzon J, Aarskog D, 1987 45,X/46,XY mosaicism. A clinical review and report of ten cases. Eur J Pediatr 146: 266-271.

9. Richter-Unruh A, Knauer-Fischer S, Kaspers S, Albrecht B, Gillessen-Kaesbach G, Hauffa BP, 2004 Short stature in children with an apparently normal male phenotype can be caused by $45, \mathrm{X} / 46, \mathrm{XY}$ mosaicism and is susceptible to growth hormone treatment. Eur J Pediatr 163: 251-256.

10. Jacobsen CM, Cohen LE, 2008 Short stature in a phenotypic male caused by mixed gonadal dysgenesis. Nat Clin Pract Endocrinol Metab 4: 524-528.

11. Lee CF, Su PH, Chen JY, Chen SJ, Yang KC, Lin LL, 2006 Short stature in patients with $45, \mathrm{X} / 46, \mathrm{XY}$ mosaicism: report of three cases. Acta Paediatr Taiwan 47: 312-316.

12. Sinnecker GH, Hiort O, Dibbelt L, et al, 1996 Phenotypic classification of male pseudohermaphroditism due to steroid 5alpha-reductase 2 deficiency. Am J Med Genet 63: 223-230.

13. Bertino E, Spada E, Occhi L, et al, 2010 Neonatal anthropometric charts: the Italian neonatal study compared with other European studies. J Pediatr Gastroenterol Nutr 51: 353-361.

14. Tanner JM, Whitehouse RH, 1976 Clinical longitudinal standards for height, weight, height velocity, weight velocity, and stages of puberty. Arch Dis Child 51: 170-179.

15. Greulich WW, Pyle SI 1959 Radiographic atlas of skeletal development of the hand and wrist. Stanford University Press, Stanford.

16. Bayley N, Pinneau SR, 1952 Tables for predicting adult height from skeletal age: revised for use with the Greulich and Pyle standards. J Pediatr 40: 432-441.

17. Bertelloni S, Baroncelli GI, Dati E, et al, 2013 IGF-I generation test in prepubertal children with Noonan syndrome due to mutations in the PTPN11 gene. Hormones (Athens) 12: 86-92.

18. Ranke MB, Pflüger H, Rosendahl W, et al, 1983 Turner syndrome: spontaneous growth in 150 cases and review of the literature. Eur J Pediatr 141: 81-88.

19. Boguszewski MC, Mericq V, Bergada I, et al, 2011 Latin American consensus: children born small for gestational age. BMC Pediatr 11: 66.

20. Binder G, 2011 Short stature due to SHOX deficiency: genotype, phenotype, and therapy. Horm Res Paediatr 75: 81-89.

21. Blum WF, Cao D, Hesse V, et al, 2009 Height gains in response to growth hormone treatment to final height are similar in patients with SHOX deficiency and Turner syndrome. Horm Res 71: 167-172.

22. Iughetti L, Vannelli S, Street ME, et al, 2012 Impaired GH secretion in patients with SHOX deficiency and efficacy of recombinant human GH therapy. Horm Res Paediatr 78: 279-287.

23. Bondy CA; Turner Syndrome Study Group, 2007 Care of girls and women with Turner syndrome: a guideline of the Turner Syndrome Study Group. J Clin Endocrinol Metab 92: 10-25.

24. Blum WF, Ross JL, Zimmermann AG, et al, 2013 GH treatment to final height produces similar height gains in patients with SHOX deficiency and Turner syndrome: results of a multicenter trial. J Clin Endocrinol Metab 98: E1383-1892.

25. Kirsch S, Weiss B, De Rosa M, Ogata T, Lombardi G, Rappold GA, 2000 FISH deletion mapping defines a single location for the Y chromosome stature gene, GCY. J Med Genet 37: 593-599.

26. Dati E, Valetto A, Bertini V, et al, 2011 45,X maleness: clinical and cytogenetic features in two patients. Sex Dev 5: 281-286.

27. Kolios G, Moodley Y, 2013 Introduction to stem cells and regenerative medicine. Respiration 85: 3-10. 